\title{
The use of herbal medicines among chronic disease patients in Thailand: a cross-sectional survey
}

This article was published in the following Dove Press journal:

Journal of Multidisciplinary Healthcare

\section{Karl Peltzer' \\ Supa Pengpid ${ }^{1,2}$}

'Deputy Vice Chancellor Research and Innovation Office, North West University, Potchefstroom, South Africa;

${ }^{2}$ Asean Institute for Health Development, Mahidol University, Salaya,

Phutthamonthon, Nakhonpathom, Thailand
Correspondence: Karl Peltzer Deputy Vice Chancellor Research and Innovation Office, North-West University, Potchefstroom Campus, II Hoffman Street, Potchefstroom 253I, South Africa

Email kfpeltzer@gmail.com
Background: The study aimed to assess the prevalence and correlates of herbal medicine use among chronic disease patients in health care settings in Thailand.

Methods: In a cross-sectional study, 1374 adult chronic disease patients (median age 60 years) were consecutively sampled from health care facilities in Thailand. Logistic regression was used to estimate the independent predictors of herbal medicine use in the past 12 months.

Results: The prevalence of herbal medicine use in the past 12 months was $35.9 \%$. Of participants who were using herbal medicine in the past 12 month, 53.7\% used it for treating a long-term health condition, $40.0 \%$ used herbal medicine in order to improve well-being and $6.3 \%$ for treating an acute illness. More than half of the herbal medicine users (57.2\%) rated their herbal medicine use as very helpful, $33.3 \%$ as somewhat helpful and $6.5 \%$ not at all helpful or do not know. In adjusted logistic regression analysis, having Grade 6 to 12 education (Odds Ratio-OR: 1.71, Confidence Interval-CI: 1.04, 2.82), rural residence (OR: 0.76, CI: 0.60, 0.97), other religion (OR: 0.57, CI: $0.35,0.97$ ), anxiety (OR: $1.64, \mathrm{CI}: 1.25,2.16)$, low quality of life (OR: $0.42, \mathrm{CI}: 0.31,0.56)$ and having multiple chronic conditions (OR: 1.82, CI: 1.30, 2.56) were associated with past 12-month herbal medicine use. Further, in adjusted logistic regression analysis, having arthritis, asthma, cancer, cardiovascular disease, dyslipidaemia, gastrointestinal disease, dyslipidaemia were positively and hypertension negatively associated with past 12-month herbal medicine use.

Conclusions: The study found a high prevalence of herbal medicine use among chronic disease patients in Thailand. Several factors (education, rural residence, anxiety, low quality of life and multiple chronic conditions) associated with herbal medicine use were identified. This knowledge will support health care providers and policy makers in decision making on the use of herbal medicine.

Keywords: herbal medicine, utilization, chronic disease patients, Thailand

\section{Introduction}

A large group of the population in "Association of Southeast Asian Nations (ASEAN)" states utilize traditional medicine. ${ }^{1}$ The World Health Organization ${ }^{2}$ highlights the relevance of studying the prevalence and correlates of traditional, including herbal medicine use.

Traditional herbal medicines are naturally occurring, plant-derived substances with minimal or no industrial processing that have been used to treat illness within local or regional healing practices. ${ }^{3}$

Under the Universal Health care Coverage Scheme of the National Health Security Office in Thailand, the treatment and rehabilitation with traditional herbal medicines or traditional recipes composing of medicinal plant materials is included. ${ }^{4}$ 
Although many populations in ASEAN countries reported to use herbal medicine to improve their health, there is limited data on Thailand. ${ }^{2,5}$

In Thailand, $10 \%$ of patients attending public health facilities receive various forms of Thai traditional medicine, including traditional herbal medicines. ${ }^{6}$ In a study a among hospital patients in Bangkok, 28.6\% had used herbal medicines. ${ }^{7}$ Among 200 medical in- and out-patients in Bangkok, $52.5 \%$ had used at least one form of alternative medicine (mostly herbal medicine) ${ }^{8}$ In a household survey in Bangkok, the prevalence of past 6-month herbal and dietary supplement use was $52.0 \% .{ }^{9}$ Several studies in Thailand found a high prevalence of herbal medicine use in patients with specific chronic conditions, eg, among 50 admitted and 50 walk-in gynaecologic cancer patients $27.0 \%$ used herbal medicines, ${ }^{10}$ past 12 -month use of $31.1 \%$ in cancer patients undergoing radiotherapy, ${ }^{11}$ among diabetes patients past 3month use of $20.1 \%$ took herbal medicine, ${ }^{12}$ past 12 -month use of $27.3 \%$ in Thai outpatients with chronic kidney disease, ${ }^{13}$ and among persons living with HIV, $32 \%$ had ever taken herbal treatment. ${ }^{14}$ We did not find any study in Thailand investigating the prevalence and correlates of herbal medicine in chronic disease patients in general. Some investigations found that herbal medicine users were more likely to have one or multiple chronic conditions. ${ }^{15}$

The prevalence of past 12-month herbal medicine use among chronic disease patients in Cambodia was $44.5 \%,{ }^{16}$ in Lao PDR 21.3\%, ${ }^{17}$ in Malaysia $24.9 \%,{ }^{18}$ Myanmar 53.2\%, ${ }^{19}$ and Vietnam $43.6 \%{ }^{20}$ Factors associated with herbal medicine use may include sociodemographic and well-being factors. Sociodemographic factors include, women, ${ }^{21,22}$ younger or older age, ${ }^{20-22}$ higher socioeconomic status, ${ }^{21,22}$ lower education, ${ }^{16}$ married, ${ }^{21}$ and urban residence. ${ }^{20}$ Well-being factors include, perceived poor health status, ${ }^{20,21}$ neither poor nor good quality of life, ${ }^{16}$ anxiety, ${ }^{23}$ depression, ${ }^{23}$ multiple chronic conditions, ${ }^{20,22}$ arthritis, ${ }^{23}$ hypertension, ${ }^{16}$ and gastrointestinal diseases. $^{16}$

Commonly used herbal medicines utilized by chronic disease patients in Lao PDR included "Moringa pterygosperma, Curcuma longa L., Curcuma xanthorrhiza, Centella asiatica L. Mushroom's Linchi, Morinda citrifolia L." ${ }^{, 17}$ in Myanmar "Ganoderma lucidum, Menispermumdauricum, Garcinia mangostana, Asiatic Penny-wort, Aloe Vera L." ${ }^{\prime 19}$ Vietnam "Curcumin, Gynostemma pentaphyllum, Ganoderma lucidum, Aloe Vera, Artichoke, Globe artichoke Cynara scolymus L.,1753,- Asteraceae and Styphnolobium japonicum. ${ }^{, 20}$ Among hospital patients in Thailand commonly used herbal medicines included "Zingiber officinale, Andrographis paniculata, Zingiber cassumunar, Capsicum frutescens and Curcuma longa". ${ }^{7}$ In a household survey in Bangkok, herbal medicines used included "Andrographis paniculata, Curcuma Longa, Moringa spp., Aloe vera, and Boensenbergia spp," and among Thai chronic kidney disease patients commonly used herbs included "Andrographis paniculata, Curcum longa, and Moringa oleifera". ${ }^{3}$ The Ministry of Public Health in Thailand has included "71 herbal medicinal products into the National List of Essential Drugs.,"23,24

The study aimed to assess the prevalence and correlates of herbal medicine use among chronic disease patients in health care settings in Thailand.

\section{Methods \\ Design}

In a cross-sectional survey, out-patients with chronic diseases in rural and urban health facilities in Thailand were interviewed.

\section{Sample and procedure}

Using consecutive sampling, chronic disease patients (21 years and older) were recruited from conveniently selected seven district hospitals across the whole country, more details have been described. ${ }^{5}$ Briefly, health facility staff conducted screening of two inclusion criteria (minimum age of 21 years and who had been treated in the past 12 months for any of 20 chronic conditions) and referred all eligible patients to the interviewers for data collection. ${ }^{5}$ Trained research assistants conducted interviews with the patients at the health care facilities, using structured questionnaires. ${ }^{5}$ The questionnaire was pre-tested for validity on a sample of 20 patients, which did not form part of the final sample. Written informed consent was obtained from each participant, and privacy and confidentially of the respondents were strictly protected. The "Committee of Research Ethics (Social Sciences) of Mahidol University (COA. No.: 2014/193.0807)" approved the study protocol. The World Medical Association Declaration of Helsinki regarding ethical conduct of research involving human subjects was followed. The sample size included at least 1300 chronic disease patients, for an estimated prevalence of $25 \%$ herbal use with precision of $\pm 2 \%$.

\section{Measures}

The "International questionnaire to measure use of complementary and alternative medicine" (I-CAM-Q) ${ }^{25}$ was used to assess the prevalence, purpose and benefits of past 12-month herbal medicine use. In addition, they were 
"asked about the names of herbal medicines they are using, their purpose, form, usage and how obtained."13

Chronic diseases were assessed from a list of 22 conditions, such as diabetes and hypertension.,26

Sociodemographic variables included sex, age, educational level, marital status, religious affiliation, and residence status. $^{5}$

Anxiety and depression was assessed with the "Hospital Anxiety and Depression Scale (HADS)", and participants scoring 11 or more on the HADS were classified as having moderate to severe anxiety and depression, respectively. ${ }^{27}$ ( $\alpha$ anxiety: $0.90 ; \alpha$ depression: 0.71 ).

Problem drinking was assessed with the "Alcohol Use Disorder Identification Test (AUDIT)-C", with scores of four or more defining problem drinking. ${ }^{28}$ ( $\alpha$ 0.72).

Health related quality of life (HRQol) was assessed with the "World Health Organization Quality of Life (WHOQol)-8,"29 and grouped into low, moderate and high HRQoL. ( $\alpha$ 0.87).

Anticipated stigma was measured with the 12-item Chronic Illness Anticipated Stigma Scale (CIASS). ${ }^{30}$ The 12 CIASS items (range from $1=$ very unlikely to $5=$ very likely) are added up, and dichotomized based on a median score of 21 or more representing anticipated chronic disease stigma. ${ }^{31}$ ( $\left.\alpha 0.92\right)$.

\section{Data analysis}

Frequencies, means, medians, standard deviations, and interquartile range were calculated to describe the sample. Chisquare tests were used to assess differences in proportion. Logistic regression was used to estimate the independent predictors (age, gender, marital status, residence type, religious affiliation, anxiety, depression, problem drinking, quality of life, number of chronic diseases and chronic disease stigma) of herbal medicine use in the past 12 months. Variables found significant $(P<0.05)$ in bivariate analysis were subsequently included in the multivariable regression model. $P<0.05$ was considered significant. Statistical procedures were conducted using "IBM SPSS Statistics for Windows" (Version 25.0. Armonk, NY: IBM Corp.).

\section{Results}

\section{Sample characteristics}

Of 1416 participants approached, 1396 agreed to take part in the study (98.6\% response rate) and 1374 had complete information on herbal medicine use. The median age of participants was 60 years (interquartile range $=16$ years, range 21-99 years), 60.8\% were women, 61.6\% had less than Grade 6 education, 94.7\% were Buddhist and 50.4\% resided in rural areas. About one in four of the participants (26.6\%) had anxiety, $20.3 \%$ depression, $4.5 \%$ problem drinking, and $48.9 \%$ had high quality of life. Respondents had been treated in the past 12 months for hypertension $(61.0 \%)$, followed by diabetes mellitus (34.9\%), dyslipidaemia (29.7\%), gout and other musculoskeletal conditions, such as chronic backache $(15.0 \%)$, cardiovascular disorder $(12.9 \%)$, arthritis $(4.8 \%)$, asthma $(4.2 \%)$ migraine or frequent headaches $(4.1 \%)$, gastrointestinal disease $(2.9 \%)$, thyroid disease $(2.8 \%)$, kidney disease $(2.5 \%)$, chronic obstructive pulmonary disease $(2.3 \%)$, Parkinson's disease $(2.1 \%)$, mental disorder $(1.9 \%)$, liver disease (1.5\%), cancer $(1.2 \%)$, and epilepsy $(0.6 \%)$. About one-third of the participants $(30.5 \%)$ had one chronic disease, $30.2 \%$ two and $39.3 \%$ three of more chronic diseases. The prevalence of past 12 -month herbal medicine use was $35.9 \%$. Of participants who were using herbal medicine in the past 12 month, $53.7 \%$ used it for treating a long-term health condition ( $>$ one month), $40.0 \%$ used herbal medicine in order to improve well-being and $6.3 \%$ for treating an acute illness (<one month). More than half of the herbal medicine users $(57.2 \%)$ rated their herbal medicine use as very helpful, $33.3 \%$ as somewhat helpful and $6.5 \%$ not at all helpful or do not know. In bivariate analysis, gender $(P=0.003)$, education $(P=0.018)$, marital status $(P=0.042)$, residence $(P=0.008), \quad$ religious affiliation $\quad(P=0.009)$ anxiety $(P<0.001)$, quality of life $(P<0.001)$ and number of chronic conditions $(P<0.001)$ were associated with past 12 -month herbal medicine use (see Table 1).

\section{Associations with herbal medicine use by sociodemographic and well-being factors}

In adjusted logistic regression analysis, having Grade 6 to 12 education (Odds Ratio-OR: 1.71, Confidence IntervalCI: $1.04,2.82)(P=0.036)$, rural residence (OR: 0.76, CI: $0.60,0.97)(P=0.026)$, other religion (OR: 0.57, CI: 0.35, 0.97) $(P=0.039)$, anxiety (OR: $1.64, \mathrm{CI}: 1.25,2.16)$ $(P<0.001)$, low quality of life (OR: $0.42, \mathrm{CI}: 0.31,0.56)$ $(P<0.001)$ and having multiple chronic conditions $(\mathrm{OR}$ : 1.82, CI: $1.30,2.56)(P<0.001)$ were associated with past 12-month herbal medicine use (see Table 2).

\section{Associations with herbal medicine use by type of chronic disease}

In adjusted logistic regression analysis, having arthritis (OR: 5.51, CI: 3.12, 9.73), asthma (OR: 2.15, CI: 1.24, 
Table I Sample characteristics

\begin{tabular}{|c|c|c|c|c|}
\hline \multirow[t]{3}{*}{ Variable } & \multirow{2}{*}{$\begin{array}{l}\text { Sample } \\
\text { All }\end{array}$} & \multicolumn{2}{|c|}{ Herbal medicine use in the past 12 months } & \multirow[t]{3}{*}{$P$-value } \\
\hline & & Yes & No & \\
\hline & $\mathbf{N}(\%)$ & $\mathbf{N}(\%)$ & $\mathbf{N}(\%)$ & \\
\hline All & 1374 & 489 (35.9) & $885(64.4)$ & \\
\hline \multicolumn{5}{|l|}{ Age (in years) } \\
\hline $18-45$ & $167(12.2)$ & $53(31.7)$ & $114(68.3)$ & 0.493 \\
\hline $46-60$ & $555(40.6)$ & $204(36.8)$ & $35 I(63.2)$ & \\
\hline $6 I-101$ & $646(47.2)$ & $231(35.8)$ & $415(64.2)$ & \\
\hline \multicolumn{5}{|l|}{ Gender } \\
\hline Female & $829(60.8)$ & $276(33.3)$ & $553(66.7)$ & 0.033 \\
\hline Male & $534(39.2)$ & $208(39.0)$ & $326(61.0)$ & \\
\hline \multicolumn{5}{|l|}{ Education } \\
\hline$<$ Grade 6 & $844(61.6)$ & $280(33.2)$ & $564(66.8)$ & 0.018 \\
\hline Grade 6-12 & $308(22.5)$ & $130(42.2)$ & I78 (57.8) & \\
\hline Postsecondary & $218(15.9)$ & 78 (35.8) & $140(64.2)$ & \\
\hline \multicolumn{5}{|l|}{ Marital status } \\
\hline Married & $978(71.6)$ & $331(33.8)$ & $647(66.2)$ & 0.042 \\
\hline Never married & $388(28.4)$ & $154(39.7)$ & $234(60.3)$ & \\
\hline \multicolumn{5}{|l|}{ Residence } \\
\hline Rural & $692(50.4)$ & $270(39.0)$ & $422(61.0)$ & 0.008 \\
\hline Urban & $682(49.6)$ & $219(32.1)$ & $463(67.9)$ & \\
\hline \multicolumn{5}{|l|}{ Religious affiliation } \\
\hline Buddhist & 1297 (94.7) & $452(34.8)$ & $845(65.2)$ & 0.009 \\
\hline Other religion & $72(5.3)$ & $36(50.0)$ & $36(50.0)$ & \\
\hline Anxiety & $361(26.6)$ & $174(48.2)$ & $306(30.8)$ & $<0.001$ \\
\hline Depression & $275(20.3)$ & $110(40.0)$ & $375(34.8)$ & 0.108 \\
\hline Problem drinking & $59(4.3)$ & $20(33.9)$ & $39(66.1)$ & 0.782 \\
\hline \multicolumn{5}{|l|}{ Quality of Life } \\
\hline Low & $299(21.9)$ & $157(52.5)$ & $142(47.5)$ & $<0.001$ \\
\hline Medium & $399(29.2)$ & $122(30.6)$ & $277(69.4)$ & \\
\hline High & 667 (48.9) & $207(31.0)$ & $460(69.0)$ & \\
\hline \multicolumn{5}{|l|}{ Chronic diseases } \\
\hline One & $419(30.5)$ & $103(24.6)$ & $316(75.4)$ & $<0.001$ \\
\hline Two & $415(30.2)$ & $147(35.4)$ & $268(64.6)$ & \\
\hline Three or more & $540(39.3)$ & $234(43.4)$ & $306(56.6)$ & \\
\hline Chronic disease stigma & $1002(74.4)$ & $368(36.0)$ & $654(64.0)$ & 0.581 \\
\hline
\end{tabular}

3.73), cancer (OR: 3.24, CI: 1.13, 9.26), cardiovascular disease (OR: 1.06, CI: 1.40, 2.76), dyslipidaemia (OR: 1.31, CI: 1.00, 1.70), gastrointestinal disease (OR: 4.82 , CI: $2.33,10.01)$, and migraine or frequent headaches (OR: $1.88, \mathrm{CI}: 1.07,3.31$ ) were positively and hypertension (OR: $0.71, \mathrm{CI}: 0.55,0.91)$ negatively associated with past 12-month herbal medicine use (see Table 3).

\section{Details of herbal medicines used}

Most frequently specific herbal medicines used included a mixture of unspecified herbs for a range of problems (dia- 
Table 2 Associations with herbal medicine use by sociodemographic and well-being factors

\begin{tabular}{|c|c|c|}
\hline Variable & AOR $(95 \% \mathrm{Cl})$ & $P$-value \\
\hline \multicolumn{3}{|l|}{ Gender } \\
\hline Female & I (Reference) & \\
\hline Male & $1.27(0.98,1.6 \mathrm{I})$ & 0.067 \\
\hline \multicolumn{3}{|l|}{ Education } \\
\hline$<$ Grade 6 & I (Reference) & \\
\hline Grade 6-12 & I.7I $(1.04,2.82)$ & 0.036 \\
\hline Postsecondary & $1.20(0.93,1.56)$ & 0.163 \\
\hline \multicolumn{3}{|l|}{ Marital status } \\
\hline Married & I (Reference) & \\
\hline Never married & $1.28(0.98,1.66)$ & 0.069 \\
\hline \multicolumn{3}{|l|}{ Residence } \\
\hline Rural & I (Reference) & \\
\hline Urban & $0.76(0.60,0.97)$ & 0.026 \\
\hline \multicolumn{3}{|l|}{ Religious affiliation } \\
\hline Other religion & I (Reference) & \\
\hline Buddhist & $0.57(0.35,0.97)$ & 0.039 \\
\hline Anxiety & $1.64(1.25,2.16)$ & $<0.001$ \\
\hline \multicolumn{3}{|l|}{ Quality of Life } \\
\hline Low & I (Reference) & \\
\hline Medium & $0.47(0.33,0.66)$ & $<0.001$ \\
\hline High & $0.42(0.31,0.56)$ & $<0.001$ \\
\hline \multicolumn{3}{|l|}{ Chronic diseases } \\
\hline One & I (Reference) & \\
\hline Two & $1.53(1.11,2.11)$ & 0.0 .10 \\
\hline Three or more & $1.82(1.30,2.56)$ & $<0.001$ \\
\hline
\end{tabular}

Abbreviation: AOR, Adjusted Odds Ratio.

betes, asthma, stroke, hypertension, muscle pain, etc.), Andrograhis paniculata (Burm.f.) Wall.ex Nees for sore throat and diarrhoea, Curcum longa Linn for health tonic, digestive tonic and knee pain, Curcuma xanthorrhiza Roxb. for pre-menopause symptoms and leucorrhoea and Zingiber officinale for cold and gastrointestinal problems. The most frequent type of herbal medicine use was "crude herbs, capsules, pills, and powder", which were mainly "swallowed and making it into a drink or food using hot water". Herbal medicines were mainly obtained from own garden, hospital, folk remedy shop or stand and drug store (see Table 4).

\section{Discussion}

Findings show a high prevalence of past 12-month herbal medicine use (35.9\%) among chronic disease patients in Thailand, higher than in Lao PDR $(21.3 \%)^{17}$ and Malaysia $(24.9 \%)$, and lower than in Vietnam $(43.6 \%),{ }^{20}$ Cambodia $(44.5 \%),{ }^{16}$ and Myanmar (53.2\%). ${ }^{19}$ This high prevalence of past 12 month herbal medicine use among chronic disease patients in Thailand confirms findings of lifetime, 12-month and past 3-month herbal medicine use in different study populations in Thailand: hospital patients $28.6 \%$, ${ }^{7}$ gynaecologic cancer patients $27.0 \%,{ }^{10}$ cancer patients treated with radiotherapy past-12-month use of $31.1 \%,{ }^{11}$ diabetes patients past 3-month use of $20.1 \%,{ }^{12}$ and $42 \%$ taking herbal medicine together with modern medication, ${ }^{32}$ chronic kidney disease patients past 12 -month use of $27.3 \%,{ }^{13}$ and among persons living with HIV lifetime use of $32 \% .{ }^{14}$ Most chronic disease patients in this study reported that the use of herbal medicine was very or somewhat helpful $(93.5 \%)$, which is similar to findings from a study among chronic disease patients in Jordan ${ }^{33}$ and Malaysia. ${ }^{18}$ The high herbal medicine use in Thailand may be related to promotion of the use of herbal medicines through the "National policy on Thai traditional medicine and the implementation" as well as the "Sufficiency Health System Strategic Plan", with the 
Table 3 Associations with herbal medicine use by type of chronic disease

\begin{tabular}{|c|c|c|c|c|}
\hline \multirow[t]{2}{*}{ Chronic disease } & Sample & Herbal medicine use & \multirow[t]{2}{*}{ AOR $(95 \% \mathrm{Cl})$} & \multirow[t]{2}{*}{$P$-value } \\
\hline & $\mathbf{N}(\%)$ & $\mathbf{N}(\%)$ & & \\
\hline Arthritis & $66(4.8)$ & 47 (7I.2) & $5.51(3.12,9.73)$ & $<0.001$ \\
\hline Asthma & $57(4.2)$ & $28(49.1)$ & $2.15(1.24,3.73)$ & 0.006 \\
\hline Cancer & $16(1.2)$ & $10(62.5)$ & $3.24(1.13,9.26)$ & 0.028 \\
\hline Cardiac failure, Stroke, Coronary artery disease, Cardiac arrhythmias & $177(12.9)$ & $80(45.2)$ & $1.06(1.40,2.76)$ & $<0.001$ \\
\hline Chronic obstructive pulmonary disease (COPD) & $31(2.3)$ & $14(45.2)$ & $1.58(0.74,3.36)$ & 0.238 \\
\hline Diabetes mellitus & $480(34.9)$ & $175(36.5)$ & $1.23(0.95,1.58)$ & 0.110 \\
\hline Dyslipidaemia & $408(29.7)$ & $158(38.7)$ & $1.31(1.00,1.70)$ & 0.046 \\
\hline Epilepsy & $8(0.6)$ & $\mathrm{I}(12.5)$ & $0.23(0.03,2.07)$ & 0.191 \\
\hline Gastrointestinal disease & $40(2.9)$ & $29(72.5)$ & $4.82(2.33,10.01)$ & $<0.001$ \\
\hline Gout and other musculoskeletal conditions, such as chronic backache & $206(15.0)$ & $86(4 I .7)$ & $1.39(1.00,1.93)$ & 0.054 \\
\hline Hypertension & $838(61.0)$ & $272(32.5)$ & $0.7 I(0.55,0.91)$ & 0.007 \\
\hline Kidney disease & $35(2.5)$ & $13(37.1)$ & $0.59(0.27,1.29)$ & 0.185 \\
\hline Liver disease & $21(1.5)$ & II (52.4) & $1.88(0.76,4.68)$ & 0.175 \\
\hline Mental disorder & $26(1.9)$ & $7(26.9)$ & $0.71(0.28,1.84)$ & 0.483 \\
\hline Migraine or frequent headaches & $57(4.1)$ & $30(52.6)$ & $1.88(1.07,3.31)$ & 0.027 \\
\hline Parkinson's disease & $29(2.1)$ & $8(27.6)$ & $0.79(0.33,1.86)$ & 0.584 \\
\hline Thyroid disease & $38(2.8)$ & $16(42.1)$ & $0.97(0.47,1.97)$ & 0.923 \\
\hline
\end{tabular}

Abbreviations: AOR, Adjusted Odds Ratio; $\mathrm{Cl}$, Confidence Interval.

emphasis on the use of Thai traditional medical knowledge and being self-reliant. ${ }^{4}$

Several studies ${ }^{20-22}$ found that being a woman and younger or older age were associated with herbal medicine use, while in this study only in bivariate analysis women had a higher prevalence of herbal medicine use than men had, and no age differences were found. This study found that having completed primary education increased the odds for herbal medicine use, while in a community survey in Turkey ${ }^{22}$ higher education was positively and among chronic disease patients in Cambodia ${ }^{16}$ was negatively associated with herbal medicine use. Consistent with some studies on traditional and complementary medicine utilization, ${ }^{17,19}$ this study found that rural residence increased the odds for herbal medicine use. In this study, rural residents obtained herbal medicines more often from their own garden, folk remedy shop or stand and hospital than urban residents (analysis not shown). It is possible that herbal medicines are better accessible in rural than urban areas in Thailand. Other religion (mainly Muslim) was associated with a higher prevalence of herbal medicine use than Buddhist religion. Further research is needed to explore as to why Muslim communities rely more on herbal medicine use than Buddhist communities do.

Consistent with previous studies, ${ }^{20-23}$ this study found that poorer well-being (low health related quality of life and anxiety) and having multiple chronic conditions were associated with herbal medicine use. Some of the reasons for these findings could be a need for more frequent herbal medicine treatment, greater desire for better management of chronic conditions or greater availability of herbal medicines. ${ }^{16}$ Other reasons could be that anxious patients are more likely to seek alternative, herbal medicine, treatment in an attempt to alleviate chronic disease symptoms. ${ }^{23}$ Further, having specific chronic conditions, arthritis, asthma, cancer, cardiovascular disease, dyslipidaemia, gastrointestinal disease and migraine or frequent headaches, increased and having hypertension decreased the odds for past 12-month herbal medicine use. Previous studies also found an association between arthritis, ${ }^{20}$ gastrointestinal diseases ${ }^{14}$ cancer $^{33}$ and herbal medicine use. A previous study among chronic disease patients in Cambodia found a positive association but this study found a negative association between hypertension and herbal medicine use. It is possible that with better health care services in Thailand, Thai hypertensive patients rely more on modern than herbal medicine than their Cambodian counterparts.

Commonly herbal medicines used in this study included Andrograhis paniculata (Burm.f.) Wall.ex Nees, Curcum longa Linn, Curcuma xanthorrhiza Roxb. Zingiber officinale, Boesenbergia rotunda, Aloe vera (l.) Burm.f., Centella asiatica, some of which have also been commonly used among chronic disease patients in Jordan (Zingiber officinale), ${ }^{34}$ in Lao PDR ("Curcuma longa L., Curcuma xanthorrhiza, Centella asiatica L."), ${ }^{17}$ Vietnam (Aloe vera, Curcuma longa L.) ${ }^{20}$ chronic kidney patients in Thailand (Curcuma longa, 


\begin{tabular}{|c|c|c|c|c|c|c|c|}
\hline $\mathbf{z}$ & $a m \sim m$ & $--m a e^{-}$ & $a n$ & $-a-$ & $m m$ & $m m \sim t$ & $\stackrel{\infty}{\sim}$ \\
\hline 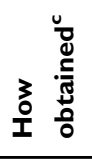 & 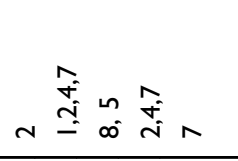 & $\sigma \wedge \sim+\stackrel{+}{\sim}$ & $n+$ & $r \stackrel{n}{n}$ & $\stackrel{5}{2}$ & $\stackrel{\dot{\Xi}}{ \pm} \underset{ \pm}{ \pm} \wedge 0$ & $\begin{array}{l}\stackrel{0}{0} \\
\text { in } \\
\stackrel{-}{-}\end{array}$ \\
\hline 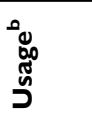 & $-\stackrel{m}{=} \stackrel{m}{m}-$ & $m-m--\stackrel{m}{-}-$ & $m-$ & --- & $\underline{m}=\underline{m}$ & $\stackrel{m}{-} m-m$ & $\stackrel{m}{=}$ \\
\hline "ृ & 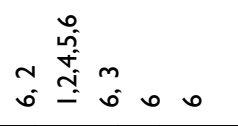 & 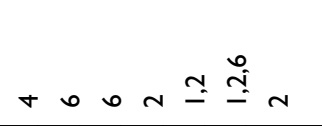 & in $N$ & ○ & 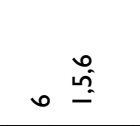 & 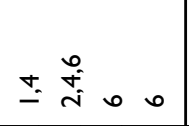 & 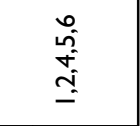 \\
\hline 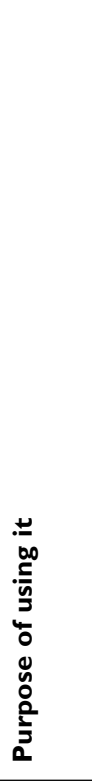 & 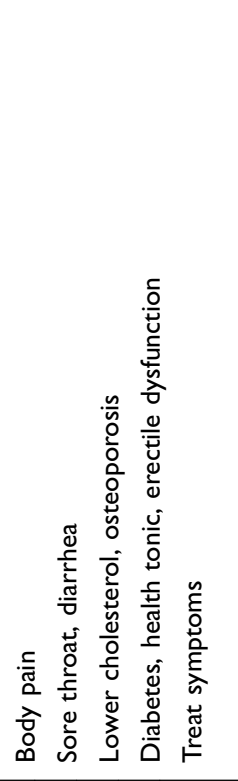 & 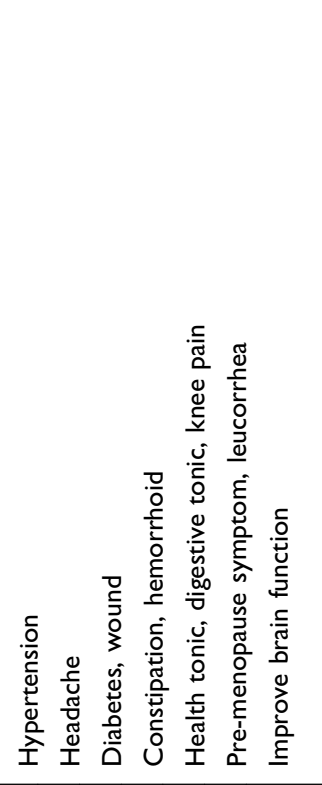 & 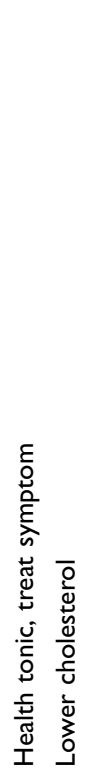 & 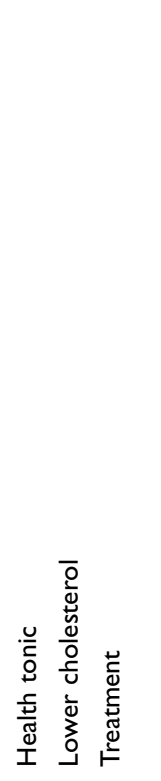 & 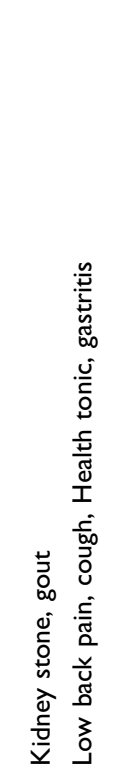 & 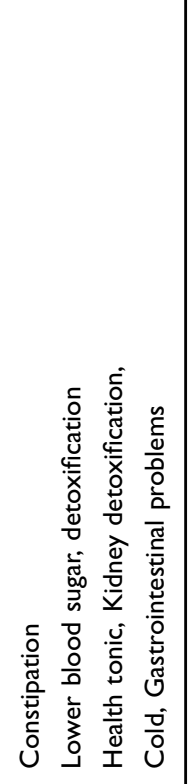 & 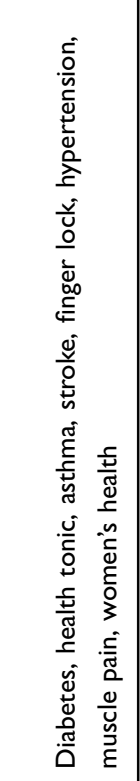 \\
\hline 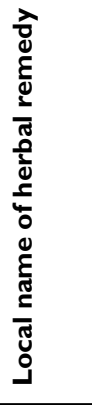 & 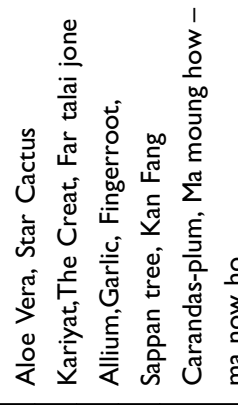 & 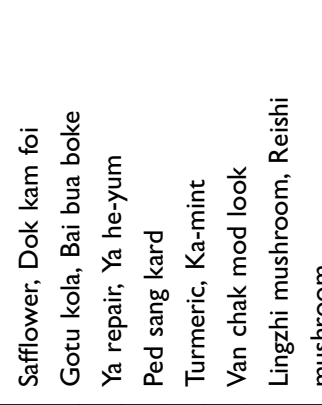 & 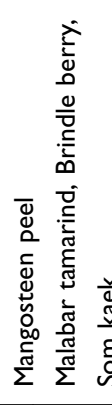 & 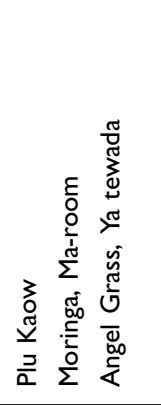 & 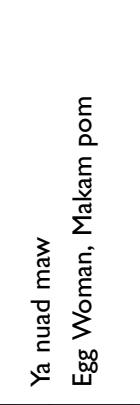 & 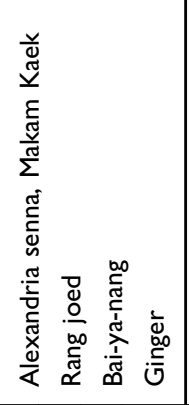 & 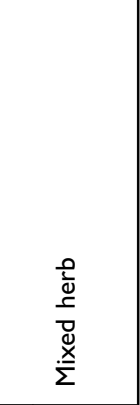 \\
\hline 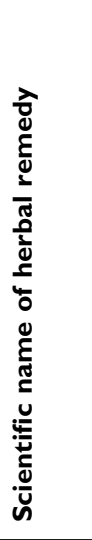 & 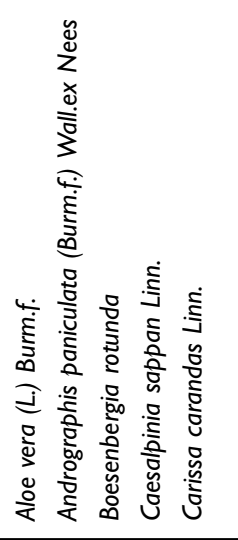 & 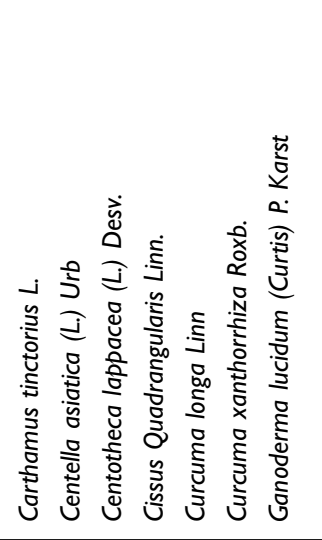 & 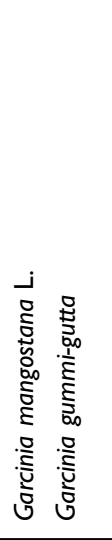 & 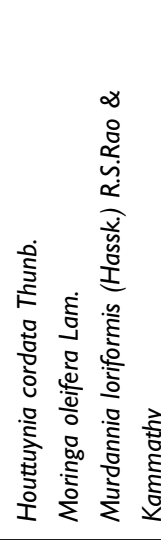 & 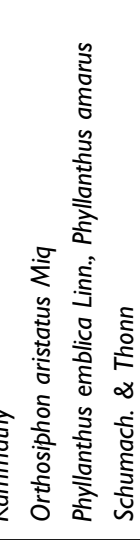 & 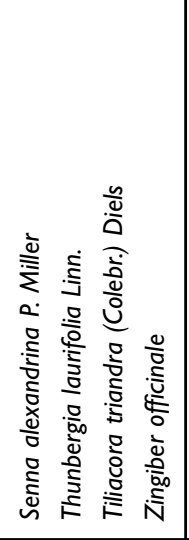 & 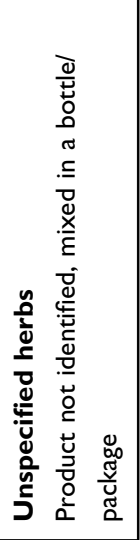 \\
\hline
\end{tabular}


Boesenbergia rotunda, Aloe vera), ${ }^{11}$ hospital patients in Bangkok (Zingiber officinale, Andrographis paniculata, Curcuma longa, Centella asiatica). ${ }^{5}$ Some of the herbal medicines used in this study are included in the national list of essential medicines in Thailand: ${ }^{35}$ Aloe vera (L.) Burm.f. (indication: burns), Andrographis paniculata (Burm. f.) Wall. ex Nees (diarrhea), Centella asiatica (L.) Urb. (wound healing) Curcuma longa L. (gastrointestinal symptoms), Garcinia mangostana L. (wounds), Murdannia loriformis (Hassk.) R.S. Rao \& Kammathy (fever), Orthosiphon aristatus (Blume) Miq. (diuretic), Senna alexandrina Mill.) (constipation), (Thunbergia laurifolia Lindl.) (fever), and Zingiber officinale Rosc. (prevent nausea and vomiting). ${ }^{35}$ Bosenbergia rotunda (L) Mansf. has anti-ulcerogenic and antioxidant effects. ${ }^{36}$ According to 2012 statistics on herbal drug use at state hospitals nationwide in Thailand was $1.82 \%$ of the total drug spending.

The top three herbal drugs commonly used by the people were curcuma or turmeric drug for the relief of flatulence or upset stomach; phlai or plai drug for muscle pain, swelling, bruise and sprain; and fa-thalai-jon drug for respiratory tract infection, cold and sore throat. ${ }^{37}$

Results showed that the two most common sources through which herbal medicines were obtained included own garden and hospitals. Satsue et al. ${ }^{38}$ found in a study in Thailand that health care provider's advice on herbal remedies and sourcing herbal medicines from hospitals were major factors contributing to herbal medicine use.

\section{Study limitations}

The study was cross-sectional, so causal conclusions can be drawn. Further, the study was conducted in selected geographic locations in Thailand, and findings cannot be generalized to other areas in Thailand. The information assessed was by self-report and may have resulted in under- or over- reporting of herbal medicine use in the past 12 months. Some aspects of importance in herbal medicine utilization, such as patient-provider communication on herbal medicine use, was not assessed, and should be assessed in future studies. The study assessed anxiety and depression using screening questionnaires, which has its limitations in terms of a correct psychiatric diagnosis.

\section{Conclusions}

The study found a high prevalence of herbal medicine use among chronic disease patients in Thailand. Several factors (education, rural residence, anxiety, low quality of life and multiple chronic conditions) associated with herbal medicine use were identified. This knowledge will support health care providers and policy makers in decision making on the use of herbal medicine.

\section{Availability of data}

The data used for this study cannot be made available in the manuscript or a public repository due to the ethical restriction. However, they can be accessed upon request from the Principal Investigator (Prof. Supa Pengpid) at supaprom@yahoo.com.

\section{Acknowledgments}

This project received support from Mahidol University, Thailand.

\section{Disclosure}

The authors report no conflicts of interest in this work.

\section{References}

1. ASEAN Secretariat. Towards harmonization of traditional medicine practices. e-Health Bull. 2012;2:1-8. Available from: www.asean.org/ ... /asean-e-health-bulletin-towards-harmonisation-of- traditionalmedicine-practices Accessed June 1, 2018.

2. World Health Organization (WHO). Global atlas of traditional medicine: Proceedings of an international meeting, 17-19 June 2003. Kobe, Japan: WHO; 2004.

3. Tilburt JC, Kaptchuk TJ. Herbal medicine research and global health: an ethical analysis. Bull World Health Organ. 2008;86(8):594-599. doi:10.2471/blt.07.042820

4. World Health Organization (WHO). Traditional medicine in the Kingdom of Thailand: the integration of Thai Traditional Medicine in the National Health Care System of Thailand, 2009. Available from: http://www.searo.who.int/entity/medicines/topics/traditional_ medicines_in_the_kingdom_of_thailand.pdf. Accessed June 20, 2019.

5. Peltzer K, Pengpid S, Puckpinyo A, Yi S, Anh LV. The utilization of traditional, alternative and complementary medicine for non-communicable diseases and mental disorders in health care patients in Cambodia, Thailand and Vietnam. BMC Complement Altern Med. 2016;16(1):92. doi:10.1186/s12906-016-1078-0

6. Department for Development of Thai Traditional and Alternative Medicine, Ministry of Public Health. Thailand's TM/CAM system; 2011. Available from: http://globinmed.com/index.php?option=com content\&view $=$ article $\&$ id $=105160$ : thailand\&catid=196: country-sce nario. Accessed February 12, 2019.

7. Satyapan N, Patarakitvanit S, Temboonkiet S, Vudhironarit T, Tankanitlert J. Herbal medicine: affecting factors and prevalence of use among Thai population in Bangkok. J Med Assoc Thai. 2010;93 (Suppl 6):S139-44.

8. Jiaranaikajorn T, Panthawangkul J. Use of alternative medicines among medical patients at Siriraj hospital. Siriraj Hos Gaz. 2002;54 (10):603-610.

9. Tangkiatkumjai M, Boardman H, Walker DM. Herbal and dietary supplement use in Bangkok: a survey. J Complement Integr Med. 2014;11(3):203-211. doi:10.1515/jcim-2013-0016

10. Supoken A, Chaisrisawatsuk T, Chumworathayi B. Proportion of gynecologic cancer patients using complementary and alternative medicine. Asian Pac J Cancer Prev. 2009;10(5):779-782. 
11. Puataweepong P, Sutheechet N, Ratanamongkol P. A survey of complementary and alternative medicine use in cancer patients treated with radiotherapy in Thailand. Evid Based Complement Alternat Med. 2012;2012:670408. doi:10.1155/2012/670408

12. Moolasarn S, Sripa S, Kuessirikiet V, et al. Usage of and cost of complementary/alternative medicine in diabetic patients. J Med Assoc Thai. 2005;88(11):1630-1637.

13. Tangkiatkumjai M, Boardman H, Praditpornsilpa K, Walker DM. Prevalence of herbal and dietary supplement usage in Thai outpatients with chronic kidney disease: a cross-sectional survey. BMC Complement Altern Med. 2013;13:153. doi:10.1186/1472-6882-13-153

14. Vanlandingham M, Im-Em W, Yokota F. Access to treatment and care associated with HIV infection among members of AIDS support groups in Thailand. AIDS Care. 2006;18(7):637-646. doi:10.1080/ 09540120500277276

15. Peltzer K, Pengpid S. Utilization and practice of Traditional/ Complementary/Alternative Medicine (T/CAM) in Southeast Asian Nations (ASEAN) Member States. Stud Ethno-Med. 2015;9(2):209218. doi:10.1080/09735070.2015.11905437

16. Pearson H, Fleming T, Chhoun P, Tuot S, Brody C, Yi S. Prevalence of and factors associated with utilization of herbal medicines among outpatients in primary health centers in Cambodia. BMC Complement Altern Med. 2018;18(1):114. doi:10.1186/s12906-018-2181-1

17. Peltzer K, Sydara K, Pengpid S. Traditional, complementary and alternative medicine use in a community population in Lao PDR. Afr J Tradit Complement Altern Med. 2016;13(3):95-100. doi:10.4314/ajtcam.v3i3.12

18. Hasan SS, Ahmed SI, Bukhari NI, Loon WC. Use of complementary and alternative medicine among patients with chronic diseases at outpatient clinics. Complement Ther Clin Pract. 2009;15(3):152157. doi:10.1016/j.ctcp.2009.02.003

19. Peltzer K, Oo WM, Pengpid S. Traditional, complementary and alternative medicine use of chronic disease patients in a community population in Myanmar. Afr J Tradit Complement Altern Med. 2016;13(3):150-155. doi:10.4314/ajtcam.v3i3.18

20. Peltzer K, Huu TN, Ngoc NB, Pengpid S. The use of herbal remedies and supplementary products among chronic disease patients in Vietnam. Stud Ethno-Med. 2017;11(2):137-145. doi:10.1080/ 09735070.2017 .1305230

21. Aziz Z, Tey NP. Herbal medicines: prevalence and predictors of use among Malaysian adults. Complement Ther Med. 2009;17:44-50. doi:10.1016/j.ctim.2008.04.008

22. Nur N. Knowledge and behaviours related to herbal remedies: a cross-sectional epidemiological study in adults in Middle Anatolia, Turkey. Health Soc Care Community. 2010;18(4):389-395. doi:10.1111/j.1365-2524.2010.00911.x

23. Chokevivat V, Chuthaputti A, Khumtrakul $P$ The use of traditional medicine in the Thai health care system, 2009. Available from: http:// www.searo.who.int/entity/medicines/topics/traditional_medicines_ in the kingdom_of thailand.pdf. Accessed April 1, 2019.

24. National Health Security Office. NHSO annual report fiscal year 2014; 2015. Available from: https://www.nhso.go.th/eng/files/user files/file/2018/001/NHSO\%20Annual\%20Report\%202014.pdf. Accessed April 12, 2019.

25. Quandt SA, Verhoef MJ, Arcury TA, et al. Development of an international questionnaire to measure use of complementary and alternative medicine (I-CAM-Q). J Altern Complement Med. 2009;15(4):331-339. doi:10.1089/acm.2008.0521
26. Lee GB, Charn TC, Chew ZH, Ng TP. Complementary and alternative medicine use in patients with chronic diseases in primary care is associated with perceived quality of care and cultural beliefs. Fam Pract. 2004;21(6):654-660. doi:10.1093/fampra/cmh613

27. Zigmond AS, Snaith RP. The hospital anxiety and depression scale. Acta Psychiatrica Scandinavia. 1983;67(6):361-370. doi:10.1111/ j.1600-0447.1983.tb09716.x

28. Bush K, Kivlahan DR, McDonell MB, Fihn SD, Bradley KA. The AUDIT alcohol consumption questions (AUDIT-C): an effective brief screening test for problem drinking. Ambulatory Care Quality Improvement Project (ACQUIP). Alcohol Use Disorders Identification Test. Arch Intern Med. 1998;158:1789-1795.

29. Schmidt S, Mühlan H, Power M. The EU-ROHIS-QOL 8-item index: psychometric re-sults of a cross-cultural field study. Eur J Public Health. 2006;16(4):420-428. doi:10.1093/eurpub/cki155

30. Earnshaw VA, Quinn DM, Kalichman SC, Park CL. Development and psychometric evaluation of the chronic illness anticipated stigma scale. J Behav Med. 2013;36:270-282. doi:10.1007/s10865-0129422-4

31. Peltzer K, Pengpid S. Anticipated stigma in chronic illness patients in Cambodia, Myanmar and Vietnam. Nagoya J Med Sci. 2016;78 (4):423-435. doi:10.18999/nagjms.78.4.423

32. Pimpa TM, Imami A, Tan Sakun S. Herbal drug use behavior of diabetic patients, Kanchanaburi Province. J Boromarajonani College Nurs. 2014;30(3):14-25.

33. Bishop FL, Lewith GT. Who Uses CAM? A Narrative review of demographic characteristics and health factors associated with CAM use. Evid Based Complement Alternat Med. 2010;7(1):11-28. doi:10.1093/ecam/nen023

34. Wazaify M, Alawwa I, Yasein N, Al-Saleh A, Afifi FU. Complementary and alternative medicine (CAM) use among Jordanian patients with chronic diseases. Complement Ther Clin Pract. 2013;19(3):153-157. doi:10.1016/j.ctcp.2013.03.001

35. Thai Food \& Drug Administration. Ministry of Public Health. Thailand. National list of Essential Medicines 2017. Thai FDA, Ministry of Public Health., Thailand; 2017. Available from: http:// www.ratchakitcha.soc.go.th/DATA/PDF/2560/E/119/27.PDF. Accessed April 11, 2019.

36. Neamsuvan O, Tuwaemaengae T, Bensulong F, Asae A, Mosamae K. A survey of folk remedies for gastrointestinal tract diseases from Thailand's three southern border provinces. J Ethnopharmacol. 2012;144(1):11-21. doi:10.1016/j.jep.2012.07.043

37. Limpananont J, Tungkwampian W. Herbal Drug System and Thai Traditional Drug Utilization. In: Somchai Nichpanit S, editor. Thai Traditional and Alternative Health Profile: Thai Traditional Medicine, Indigenous Medicine and Alternative Medicine 20112013. Nonthaburi Department for Development of Thai Traditional and Alternative Medicine, Ministry of Public Health, 2557;119-142. Available from: http://164.115.27.97/digital/files/original/ f662088b1fec03a26d28d72d54b2928a.pdf.

38. Satsue S, Promponjorn K, Rakpurk W. Survey of factors affecting herbal medicine consumption behavior among people in Sai Noi district, Nonthaburi Province. J Thai Tradit Altern Med. 2018;16 (3):463-473. 


\section{Publish your work in this journal}

The Journal of Multidisciplinary Healthcare is an international, peerreviewed open-access journal that aims to represent and publish research in healthcare areas delivered by practitioners of different disciplines. This includes studies and reviews conducted by multidisciplinary teams as well as research which evaluates the results or conduct of such teams or healthcare processes in general. The journal covers a very wide range of areas and welcomes submissions from practitioners at all levels, from all over the world. The manuscript management system is completely online and includes a very quick and fair peer-review system. Visit http://www.dovepress.com/testimonials. php to read real quotes from published authors. 